\title{
Interface design for monitoring and estimation system for flooding through an image analysis of remote sensing (SAVUI)
}

\section{Diseño de interfaz para el sistema de monitoreo y estimación de inundaciones a través de un análisis de imágenes de percepción remota (SAVUI)}

\author{
YAÑEZ-VARGAS, Israel†*', GONZÁLEZ-RAMÍREZ, Andrea“, ASTUDILLO-MONTENEGRO, \\ Felipe' and FLORES-GARCÍA, Jaqueline'
}

Universidad Politécnica de Juventino Rosas, Telematics Engineering Department, Mexico.

"CINVESTAV, IPN, Unidad Guadalajara, Telecommunications Laboratory, Mexico.

ID $1^{\text {st }}$ Author: Juan Israel, Yañez-Vargas / ORC ID: 0000-0001-5749-8442, CVU CONACYT- ID: 295711

ID $1^{\text {st }}$ Coauthor: Andrea, González-Ramírez /ORC ID: 0000-0001-9961-4763, CVU CONACYT- ID: 1001207

ID $2^{\text {nd }}$ Coauthor: Felipe, Astudillo-Montenegro / ORC ID: 0000-0001-5561-7735

ID $3^{\text {rd }}$ Coauthor: Jaqueline, Flores-García / ORC ID: 0000-0002-2685-5985

\begin{abstract}
In recent years the floods in Mexico caused economic and human losses, therefore, it is necessary to use the possible tools that can provide help to the government to reduce damage from natural disasters. For this, we decided to develop a graphical user interface, known as GUI in Matlab for the segmentation of SAR, Multispectral and POLSAR images, with the intention of detecting flooding and vulnerable areas to flooding. The designed software compute a rivers segmentation in order to make the comparison between image with flooding and the image without flooding from the same area, and to obtain a visually result where a projection of the vulnerable areas to flooding in the original image this with help of basic segmentation algorithms such as grayscale, binarization, dilation, wavelet, normalization, filtering and edge detection.
\end{abstract}

\section{Resumen}

En los últimos años, las inundaciones en México causaron pérdidas económicas y humanas, por lo tanto, es necesario utilizar las posibles herramientas que pueden proporcionar ayuda al gobierno para reducir los daños causados por los desastres naturales. Para esto, decidimos desarrollar una interfaz gráfica de usuario, conocida como GUI en Matlab para la segmentación de imágenes SAR, Multiespectrales y POLSAR, con la intención de detectar inundaciones y áreas vulnerables a las inundaciones. El software diseñado calcula una segmentación de ríos para hacer la comparación entre la imagen con inundación y la imagen sin inundación desde la misma área, y para obtener un resultado visual donde una proyección de las áreas vulnerables a inundación en la imagen original esto con la ayuda de algoritmos de segmentación básicos como escala de grises, binarización, dilatación, wavelet, normalización, filtrado y detección de bordes.

Imágenes SAR, Interfaz de Matlab, Inundaciones

Citation: YAÑEZ-VARGAS, Israel, GONZÁLEZ-RAMÍREZ, Andrea, ASTUDILLO-MONTENEGRO, Felipe and FLORES-GARCÍA, Jaqueline. Interface design for monitoring and estimation system for flooding through an image analysis of remote sensing (SAVUI). Journal of Technological Prototypes. 2020. 6-18:30-38.

\footnotetext{
* Correspondence to Author (Email: jyanez_ptc@upjr.edu.mx)

$\dagger$ Researcher contributing first author
} 


\section{Introduction}

Mexico suffer hundreds of human deceased and economic losses due to the constant rains, river overflows and landslides caused by storms or hurricanes, the most dangerous occurring when rivers are exceeded in their capacity and carries excess water, mud and trash to small villages, crops and cities, causing severe flooding and even death explained in INEGI (2011) and Index Mundi (2015). In recent years and with current technology is possible to prevent dangerous situations and thus increase the probabilities of reducing human and material losses when a natural disaster occurs. Aware that natural events are unavoidable, it is necessary to design a valuable tool in which, using satellite imagery, images from drones and/or air vehicles with synthetic aperture radar (SAR) systems, can be assessed in a more timely and effective way in areas damaged by disasters, with the development of software that will contain as main tools the use of image processing and the design of a friendly interface for the final user, how Popescu, Ichim $y$ Caramihale (2015) develop it.

Satellite or drone information allows not only the planning and management of recovery actions of the post-event areas, but in many cases, can issue early warnings, prior to the event. Floods emit precursor signals that a satellite can detect and that would help prevent dangerous situations. We design a software for identify rivers, flooding zones and flood predictions using image processing tools (image segmentation, a priori information of floods and images without flooding), the software aims to support federal institutions of government in Mexico such as Civil Protection, INEGI (Instituto Nacional de Estadística y Geografía in spanish), SEMAR (Secretaría de Marina in spanish), SEDENA (Secretaría de la Defensa Nacional in spanish), CONAGUA (Comisión Nacional del Agua) and any institution that has access to SAR images, images acquired by drones and/or air vehicles.

For monitoring flooding zones or areas with probability for flooding, it is necessary any tool that helps to analyse the land, population and the environment, especially with new technological advances in the remote sensing (RS) area, such as the use of images from SAR systems, LANDSAT satellites and polarimetric image (POLSAR).
For flooding segmentation and classification areas or zones with water, an analysis of RS images is required for to know the multiple features in areas with water, with the intention to get information that helps to classify, separate/segment the class mentioned above, an example is described in the research paper (Shen, Wang, Mao, Anagnostou \& Hong, 2019), where the study reviews theories and algorithms of flood inundation mapping using SAR data, together with a discussion of their strengths and limitations, focusing on the level of automation, robustness, and accuracy.

Avendano \& Bayona (2014) and Avendano, Mora, Vera, Torres \& Prieto (2015), describes that in order to prevent natural flood disasters is important to identify the flood areas. For this reason, in Colombia, Avendano propose a computational tool in MATLAB, able to detect and classify Colombia's flood zones in SAR images. They used different classifiers, and according to the performance we selected the best. The training database was generated with the results of Fuzzy Clustering, $\mathrm{K}$-means and Region -Growing segmentations on flood zones in SAR imagery. We used two different classifiers: the first one is a Bayes classifier, while the second one is a Support Vector Machine (SVM). The United States Geological Survey (USGS) Flood Inundation Mapping (FIM) (USGS, 2017) program focuses on developing one such product, a flood inundation map library, and helping communities pair that library with USGS realtime stream data and National Weather Service flood forecasts to form a two-dimensional flood warning system. Together, these products can help communities estimate the extent of the flood and identify at-risk areas and resources in advance of the floodwaters arriving, providing a powerful advantage in the effort to keep people and property safe from rising waters. In Mexico, in the University UNAM (Parrot 2013) development the software TLALOC (Threedimensional Landscape Analysis Local Operating Computation) represents a new and powerful tool for the study of morphometry and geomorphology from the use of Digital Terrain Models (DTM). In fact, DTM describes more accurately the land surface, in such a way that they offer the possibility of studying in detail the various aspects related to the shape of the relief. 
An innovative tool for remote sensing is (QGIS, 2019) (formerly also called Quantum GIS) is a free code Geographic Information System (GIS) for GNU / Linux, Unix, Mac OS, Microsoft Windows and Android platforms, the problem is that the project is for the study of map and mapping, also (ArcGIS, 2019) is general-purpose industry-standard software that not only maps data but provides many means to transform it for other purposes. Its tools can extract related features, provide geostatistical analysis, and generate 3D models and movies of time-dependent changes.

However, all the previous algorithms/softwares fail to locate flooded areas with a large percentage, in addition to not having information from multiple images of remote perception (SAR, LANDSAT and POLSAR), and it is added that they do not have an interface that allows the user Make image changes for later analysis.

For this reason, this research work explains the design of a Matlab's interface for the detection and visualization of flooding in RS images and areas with flooding probability.

\section{Remote Sensing Introduction}

In (Ryerson \& Henderson, 1998) and (Curlander \& McDonough, 1991) Remote Sensing (RS) can be defined as the science and art of obtaining information about an object by analysing the data acquired through a device that is not in physical contact with that object. RS systems, mainly used in satellites, drone and Unmanned Aerial Vehicle (UAV), provide a repetitive and consistent view of the earth that is very important in the short and long-term monitoring of the Earth's surface.

Some specific uses of RS images of the Earth include: Large forest fires can be mapped from space, allowing rangers to see a much larger area than from the ground and tracking clouds to help predict the weather or watch erupting volcanoes, and help watch for dust storms. RS contain multiple sensors or systems but for this research paper we use three imagery RS systems (SAR imagery system, Multispectral imagery system and POLSAR imagery system).

\section{SAR image}

SAR is a radar system used in space and air vehicles that uses the relative movement between the antenna and a region of interest in order to obtain a finer spatial resolution than would be obtained if the radar and the region of interest were fixed with respect to each other. (Curlander \& McDonough, 1991) and (Moreira et al., 2013). The electromagnetic pulses are sent to the ground in a direction perpendicular to the vehicle's flight and is implemented by an antenna mounted on a mobile platform or airplane from which a scene is repeatedly lit target with pulses of radio waves that can have wavelengths from one meter to millimetres.

The SAR takes advantage of the longrange propagation features of radar signals and the large information processing capacity of current digital computers to provide highresolution images.

\section{Landsat 5}

In 2012, EOS establish that Landsat 5 was a low Earth orbit satellite launched on March 1, 1984 to collect imagery of the surface of Earth. Since 1984, Landsat 5 has gathered more than 700,000 images and observed climate change, agricultural practices, development and urbanization of cities, ecosystem evolution, and increasing demand for natural resources.

Landsat Thematic Mapper (TM) sensor was carried on Landsat 4 and Landsat 5, and created images consisting of six spectral bands with a spatial resolution of 30 meters for Bands 1-5 and 7, and one thermal band (Band 6). The approximate scene size is $170 \mathrm{~km}$ north-south and $183 \mathrm{~km}$ east-west (106 mi by $114 \mathrm{mi}$ ). TM could not resolve individual houses or trees, but it could record areas where houses had been constructed or forests had been cleared.

\section{Multispectral image}

Vignesh \& Thyagharajan (2017) described that a multispectral image is a collection of several monochrome images of the same scene, each taken with a different sensor. Each image is known as a band. A well-known multispectral (or multiband) image is an RGB colour image, consisting of a red, a green and a blue image, each taken with a sensor sensitive to a different wavelength. In image processing, multispectral images are most used for remote sensing applications. Satellites generally take several images of frequency bands in the visual and non-visual range. 


\section{POLSAR Image}

Moreira et al. (2013) and Boerner (2015) depict the Polarimetric SAR is a mode of SAR imagery which transmits and receives signals of multiple polarizations rather than just one polarization.

Polarimetric SAR systems enhance the capabilities of basic radar systems by transmitting and receiving in multiple polarizations. By utilizing different polarizations, it is possible to discern unique and distinct features of targets. Some features can be observed in one polarization and not in another. Target features can be defined more clearly by combining all four polarization modes.

In other words, radar systems can transmit and receive either a Vertical (V) or a Horizontal $(\mathrm{H})$ polarization of a radio wave. Polarimetric SAR can be performed by either transmitting vertical and horizontal polarizations or receiving vertical and horizontal polarizations, or both.

\section{Background Image Processing}

In 2008, Gonzalez \& Woods and 2015, Russ \& Neal establish that an image may be defined as a two-dimensional function, $\mathbf{I}(x, y)$, where $x$ and $y$ are spatial coordinates, and the amplitude of $\mathbf{I}$ at any pair of coordinates $(x, y)$ is called the intensity or gray level of the image at the point. When $x, y$ and the amplitude values of $I$ are all finite, discrete quantities, we call the image a digital image. The field of digital image processing refers to processing the images by means of a digital computer. The next definitions explain the area of image processing and the core of the project:

\section{Grey-Scale image}

(Gonzalez \& Woods, 2018), (Russ \& Neal, 2015) describe that in image processing a greyscale image is one in which the value of each pixel is a single sample representing only an amount of light, that is, it carries only intensity information. Grayscale images, a kind of black-and-white or grey monochrome, are composed exclusively of shades of grey. The contrast ranges from black at the weakest intensity to white at the strongest, Greyscale is represented by the equation 1, where the algorithm converts RGB values to grayscale values by forming a weighted sum of the $R, G$, and $\mathrm{B}$ components:

$\mathbf{I}_{G}=0.2989 * \mathbf{R}+0.5879 * \mathbf{G}+0.114 * \mathbf{B}$

\section{Filtered image}

Filtering is a technique used for modifying or enhancing an image like highlights certain features or remove other features, image filtering includes smoothing, sharpening and edge enhancement. It may be applied in either spatial domain or frequency domain.

For the case of the remote sensing image in specific the SAR and POLSAR system the most common noise is the speckle noise that degrading the quality of the image. Therefore, and efficient speckle noise removal technique needs to be sought, the Lee Filter is the most efficient algorithm to reduce the imperfections of the speckle noise according to Moreira et al. (2013) and Yommy, Liu \& Wu (2015).

\section{Normalize image}

Normalization is a process that changes the range of pixel intensity values. It is sometimes called contrast stretching or histogram stretching. In more general fields of data processing, such as digital signal processing, it is referred to as dynamic range expansion. The normalization is represented by the equation 2 :

$\mathbf{I}_{\mathrm{N}}=(\mathbf{I}-$ Min $) *\left(\frac{\text { newMax-newMin }}{\text { Max-Min }}\right)+$ newMin

Where $\mathbf{I}_{\mathbf{N}}$ is the normalized pixel, $\mathbf{I}$ is the intensity of the original pixel, Min and Max are the minimum and maximum pixel intensity in the image to be stretched to the new intensity, and newMin and newMax are the new minimum and maximum pixel range for the normalized image (Gonzalez \& Woods, 2018), (Russ \& Neal, 2015).

\section{Edge detection (sobel)}

Edge detection is usually a stage widely used for segmentation tasks or for the search for more complex geometric objects such as lines, ellipses, corners. Edge is understood as the region where there is a strong variation in the intensity level in adjacent pixels. It is main caused by the intersection of several objects, with different levels of reflectance, which when projected on the camera generate intensity discontinuities in the corresponding pixels. However, these discontinuities also appear in an unwanted way due to the presence of noise, the effect of shadows on the objects themselves, or because of uneven lighting within the scene. 
The sobel filter is the most used algorithm for edge detection, it works by calculating the gradient of image intensity at each pixel within the image. It finds the direction of the largest increase from light to dark and the rate of change in that direction. The result shows how abruptly or smoothly the image changes at each pixel, and therefore how likely is that pixel represents and edge (Gonzalez \& Woods, 2018), (Russ \& Neal, 2015).

\section{Binary image}

Gonzalez \& Woods (2018), Russ \& Neal (2015) define that a binary image is a digital image that has only two possible values for each pixel. Typically, the two colours used for a binary image are black and white, a typical method is the Fixed Thresholding binarization method fixed threshold value is used to assign 0 's and 1's for all pixel positions in each image. Puneet \& Garg (2013) depict that the basic idea for fixed binarization method is described as under, where the $\mathbf{I}_{\mathrm{B}}$ is the Binary image, the $\mathbf{I}$ is the original image to convert to binary and $\mathrm{T}$ shows global threshold value.

$$
\mathbf{I}_{\mathrm{B}}=\left\{\begin{array}{l}
1 \text { if } \mathbf{I} \geq \mathrm{T} \\
0 \text { otherwise }
\end{array}\right.
$$

\section{Dilation image}

In (Gonzalez \& Woods, 2018), (Russ \& Neal, 2015) shown that the mathematical morphology (MM) is a theory and technique for the analysis and processing of geometrical structures, based on set theory, lattice theory, topology, and random functions. $\mathrm{MM}$ is most applied to digital images, but it can be employed as well on graphs, surface meshes, solids, and many other spatial structures. The basic morphological operators are erosion, dilation, opening and closing. Dilation usually represented by $\Theta$, originally developed for binary images, it has been expanded first to grayscale images, and then to complete lattices. The dilation operation usually uses a structuring element for probing and expanding the shapes contained in the input image explained in Sghaier, Foucher \& Lepage (2017),

$\mathbf{I} \otimes \mathbf{B}=\bigcup_{\mathrm{b} \in \mathbf{B}} \mathbf{I}_{\mathrm{b}}$,

The equation 4 represent the dilation, where $\mathbf{B}$ is a structuring element and $\mathbf{I}_{\mathrm{b}}$ is the translation of $\mathbf{I}$ by $\mathbf{b}$.

\section{Methodology}

Figure 1 shown the general flow chart for obtain the segmented flooding area and projected in the original image without flooding.

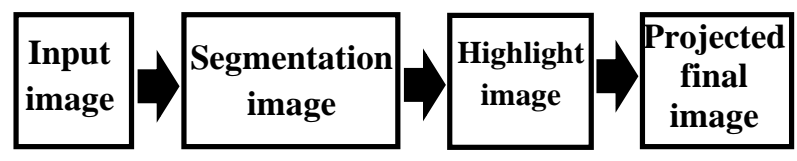

Figure 1 Principal segmentation flow chart Source: own work [power point]

In flow chart the first step corresponds to read the flooding image SAR, Multispectral or POLSAR, depend of the interface that the user selects. The second step is the image segmentation process, the next step is to paint or highlight the segmented image, last step is the final image when the highlight image is projected with the original image (without flooding).

\section{SAVUI Interface and Results}

The SAVUI interface project was designed in software Matlab® version 2016 according to the multiple Remote Sensing systems.

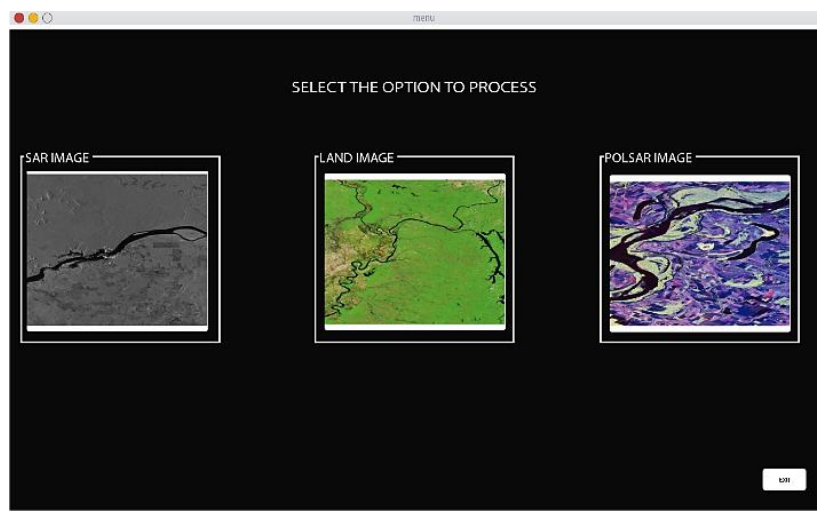

Figure 2 Principal segmentation flow chart Source: own work [Matlab]

Figure 2 is the principal software interface, where contain three different options with multiples process and algorithms, the principal idea is to segment the selected image, specially the water or places with water.

User can select the option according to the different image or images, the options are SAR image, multispectral image (LANDSAT) and POLSAR image.

The first process is when the user selects the option SAR image, where the difference between this process is that the SAR image contains information in greyscale while the other systems (images) works with RGB or multiple polarization information. 


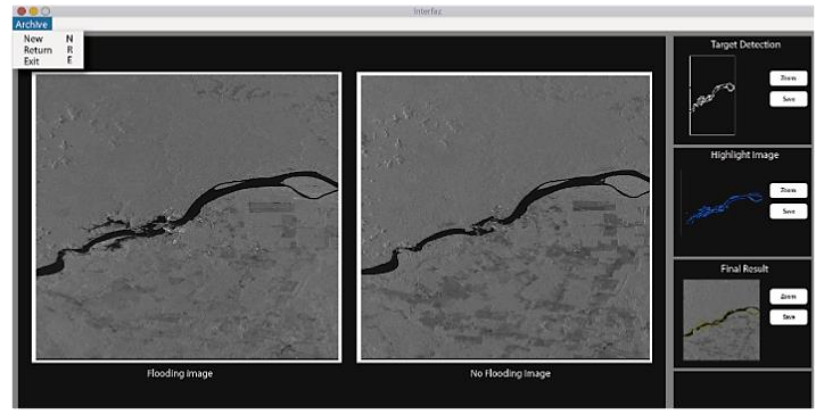

Figure 3 SAR process interface

Source: own work [Matlab]

The figure 3 depicts the SARs interface design image, in top left the user can select multiple operations, the first is to load a new image that will be process with multiple algorithms for segmentation, first space corresponds to the flooding image, after select the image, the software compute different algorithms: (RGB to grey conversion, the use of morphological operators, for this case dilation and convex components with the idea of increase and connect the neighbouring pixels, the next step is the edge detection with the algorithm of sobel and the use of Lee filter to reduce the speckle noise in the image), the second space corresponds to the original SAR image without flooding, after all the process the software shown in the right side three images: final image segmentation, highlight image and the final result.
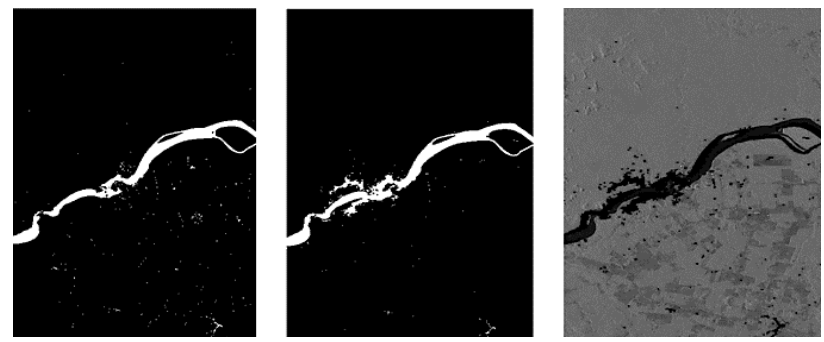

Figure 4 Final SAR segmentation Source: Own work [Matlab]

Also, in figure 4 shown an example with SAR flooding image and original image (without flooding) with the different results, in this part the user can observe that in right side the final result contain the projection of the segmented image and the original image with some areas with flooding, at the same time, the user can apply zoom (image amplification) in each process and observe some extra details, also the user can save in a computer the image in format TIFF.

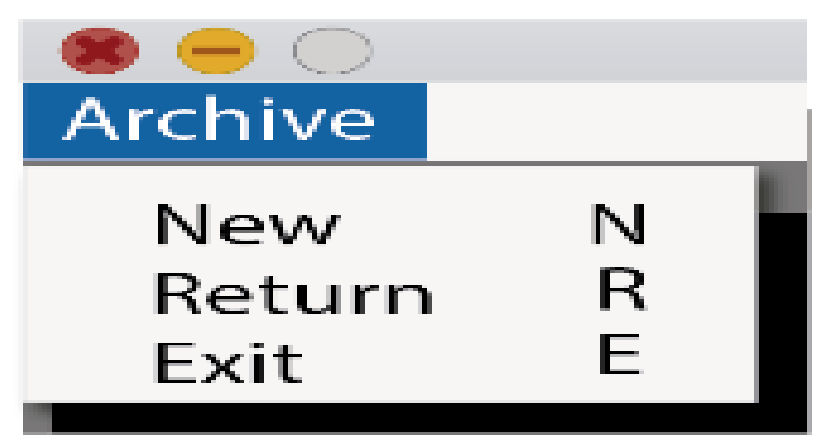

Figure 5 Example of the toolbar Source: own work [Matlab]

In figure 3 , the final segmentation is with edge information of the river, so it was decided to modify the algorithm to be able to detect the entire river, obtaining the satisfactory result that shown in the figure 4, a) segmentation of the original SAR image, b) temporal image segmentation and c) final result with estimation or vulnerable zones to flooding.

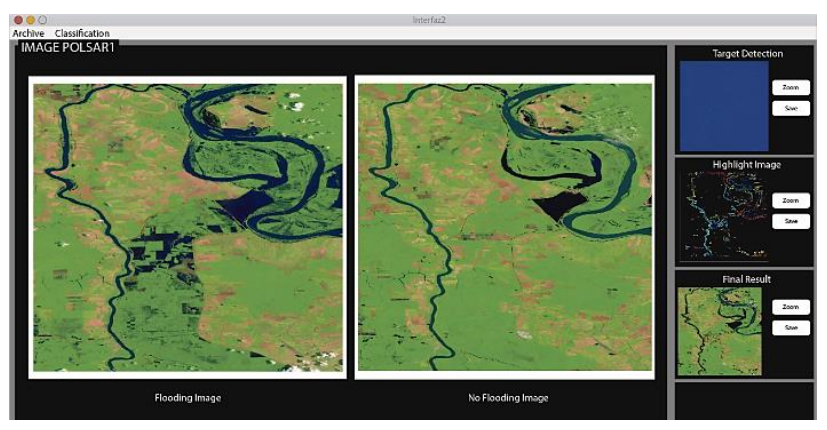

Figure 6 Example of LANDSAT 5 image Source: own work [Matlab]

In figure 5 depicts the menu of the interface with the main activities described below:

- New: open window to select/load the image to process.

- $\quad$ Return: return to the principal interface.

- $\quad$ Exit: software's exit.

The figure 6 is when the user select the LANDSAT option, in this interface we aggregate an extra example with multispectral image for most specific information the false colour RGB image, the difference between this image with SAR is the bands combination to create and image with false colour, in the final image, we projected the flooding zones segmentation with an original image for represent areas with water with multiple colour (red and blue colour). 


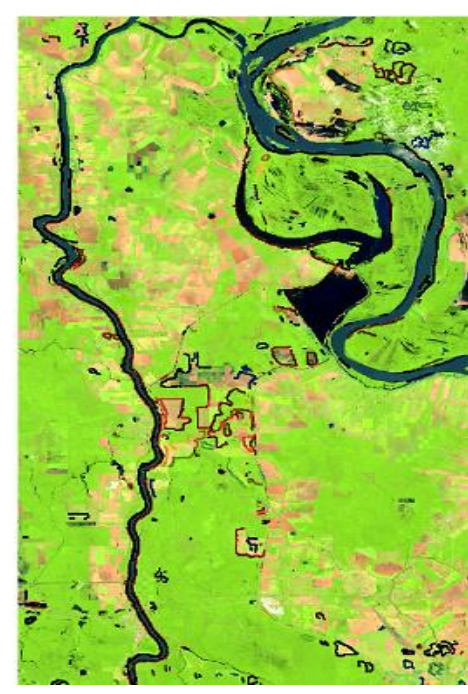

Figure 7 Final Result (Landsat 5) Source: own work [Matlab]

The figure 7 present the amplification of the result in multispectral process, for this case the user can observed areas with flooding highlighted in red colour, this figure is a projection of the segmented flooding image in the original image without flooding.

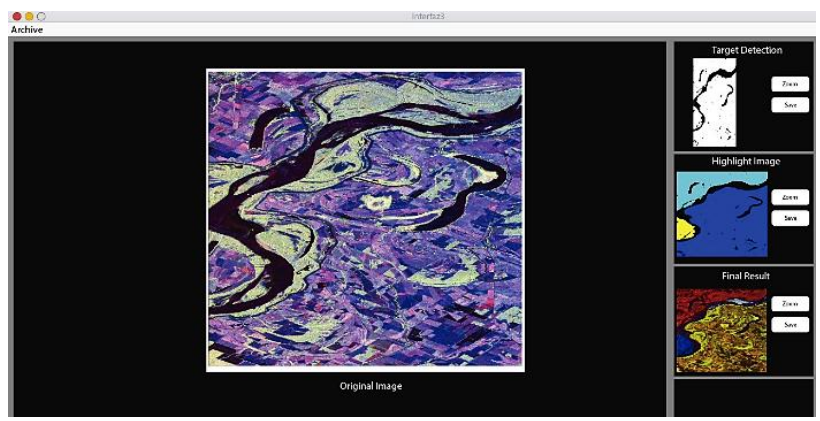

Figure 8 Example of segmentation with POLSAR image Source: own work [Matlab]

In figure 8, we have the last process when the user select the POLSAR process, in this case the interface is different because is necessary to segment with colours the important areas, the first step is to load the original image, the second step is to segment the image, the third step is to highlight the information (targets) and finally shown the result with classification in colours, this process is for algorithm validation because in this part is not necessary the original image.

The result for the previous process is displayed in figure 9, where the water is segmented in purple colour and the other elements is separated in different colours.

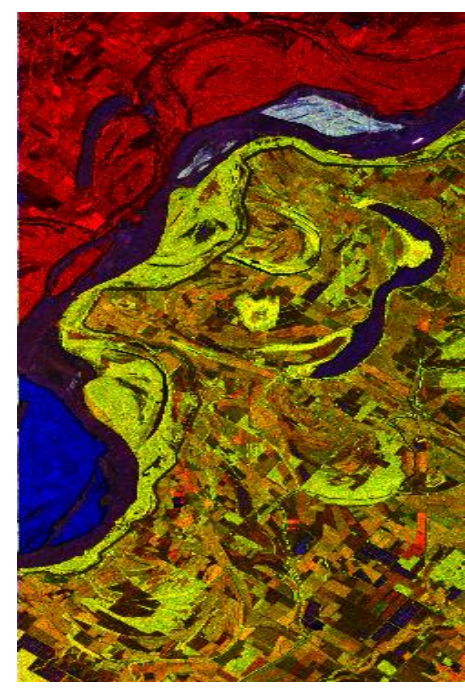

Figure 9 Final Result

Source: Own work [Matlab]

\section{Conclusions}

In this research project shows a tool that process, segmented and detect flooding in SAR, Multispectral and POLSAR images, as well as the incorporation of an GUI interface in Matlab that will facilitate user-computer communication, this through a set of instructions (algorithms) of images, buttons, bar of tools and texts. The relevant about the GUIinterfaces is that it allows the user to have control of the activities or processes to enhancement, features extraction and segmentation images. It is important to mention that the interfaces are designed to be intuitive so that the user can acquire experience and knowledge in the manipulation of Remote Sensing but specially the analyse the flooding with different sensors.

The differences to this project with a state of the art mentioned previously are the manipulations of multiple images (SAR, Multispectral and POLSAR), the comparative between the normal image and the flooding image for find the zones with more probability of flooding, for this case is necessary to acquire more images from the same scene in different times. This software is the first part of an extended project, for future work, the second part is the use of artificial intelligence for detecting flooding, also the segmentation of water, cities, vegetation and other elements, the third part of the project is to develop a software with all the previous steps in open source and the use of QT for interface design.

\section{Acknowledgment}

The authors would like to thank to the Universidad Politécnica de Juventino Rosas and the project TOLTECA ANR-CONACYT T No. 273562 


\section{References}

Argis. (2019, 1 enero). ArcGisOnline. https://www.arcgis.com/index.html

Avendano, J., \& Bayona, J. (2014). Segmentation and classification of SAR imagery on flood zones in Colombia, a computing tool for disaster prevention. Revista Facultades de Ingeniería, 48(8), 24-38. http://csifesvr.uan.edu.co/index.php/ingeuan/art icle/download/266/pdf.

Avendano, J., Mora, S., Vera, J., Torres, J., \& Prieto, F. (2015). Flood monitoring and change detection based on unsupervised image segmentation and fusion in multitemporal SAR imagery. 2015 12th International Conference on Electrical Engineering, Computing Science and Automatic Control (CCE).

Boerner, W. (2015). Future perspectives of SAR polarimetry with applications to multiparameter fully polarimetric POLSAR remote sensing \& geophysical stress-change monitoring within the equatorial/sub-equatorial belts by implementation of equatorially orbiting POLSAR single and tandem satellite sensors Focused on Malaysia and Indonesia. 2015 International Conference on Space Science and Communication (IconSpace), https://doi.org/10.1109/iconspace.2015.728380 3

Curlander, J. C., \& McDonough, R. N. (1991). Synthetic Aperture Radar: Systems and Signal Processing (Ed. rev.). New jersey, USA: Wiley. EOS. (2012, 1 enero). Landsat 5 (TM) Information, Bands, Operational Data and more. https://eos.com/landsat-5-tm/

Gonzalez, R. C., \& Woods, R. E. (2008). Digital Image Processing ( $3^{\mathrm{a}}$ ed.). USA: Pearson/Prentice Hall.

Index Mundi. (2015, 10 enero). Ranking de países por Promedio detallado de precipitaciones (mm anuales). https://www.indexmundi.com/es/datos/indicado res/AG.LND.PRCP.MM/rankings

INEGI. (2011, 18 octubre). Seminario Internacional: "Medición de Grupos Sociales Vulnerables".

https://www.inegi.org.mx/eventos/seminarios/2 011/grupos_vulnerables/
Moreira, A., Prats-Iraola, P., Younis, M., Krieger, G., Hajnsek, I., \& Papathanassiou, K. P. (2013). A tutorial on synthetic aperture radar. IEEE Geoscience and Remote Sensing Magazine, 1(1), 6-43.

Parrot, J. (2013, 1 julio). Tridimensional Landscape Analysis. Local Operating Computation. https://www.usgs.gov/missionareas/water-resources/science/flood-inundationmapping-fim-program?qtscience_center_objects $=0$

Popescu, D., Ichim, L., \& Caramihale, T. (2015). Flood areas detection based on UAV surveillance system. 2015 19th International Conference on System Theory, Control and Computing (ICSTCC).

Puneet, P., \& Garg, N. (2013). Binarization Techniques used for Grey Scale Images. International Journal of Computer Applications, 71(1), 8-11. https://doi.org/10.5120/12320-8533

QGIS. (2019, 1 enero). Bienvenido al proyecto QGIS! Recuperado 1 abril, 2020, de https://qgis.org/es/site/

Russ, J. C., \& Neal, F. B. (2015). The Image Processing Handbook ( $3^{\mathrm{a}}$ ed.). London, England: Taylor \& Francis.

Ryerson, R. A., Henderson, F. M., Lewis, A. J., \& American Society for Photogrammetry and Remote Sensing. (1998). Manual of Remote Sensing, Principles and Applications of Imaging Radar ( $3^{\mathrm{a}}$ ed.). US, US: Wiley.

Sghaier, M. O., Foucher, S., \& Lepage, R. (2017). River Extraction From High-Resolution SAR Images Combining a Structural Feature Set and Mathematical Morphology. IEEE Journal of Selected Topics in Applied Earth Observations and Remote Sensing, 10(3), 1025-1038.

https://doi.org/10.1109/jstars.2016.2609804

Shen, X., Wang, D., Mao, K., Anagnostou, E., \& Hong, Y. (2019). Inundation Extent Mapping by Synthetic Aperture Radar: A Review. Remote Sensing, 11(7), 879. https://doi.org/10.3390/rs11070879

USGS. (2017, 1 julio). Flood Inundation Mapping Science. https://www.usgs.gov/mission-areas/waterresources/science/flood-inundation-mappingscience?qt-science_center_objects $=0$ 
Vignesh, T., \& Thyagharajan, K. K. (2017). Water bodies identification from multispectral images using Gabor filter, FCM and canny edge detection methods. 2017 International Conference on Information Communication and Embedded Systems (ICICES), https://doi.org/10.1109/icices.2017.8070767

Yommy, A. S., Liu, R., \& Wu, A. S. (2015). SAR Image Despeckling Using Refined Lee Filter. 2015 7th International Conference on Intelligent Human-Machine Systems and Cybernetics,

https://doi.org/10.1109/ihmsc.2015.236 